\title{
ОТРАЖЕНИЕ МЕЖДУНАРОДНОГО ПРАВА В СОВЕТСКОЙ ТЕОРИИ ГОСУДАРСТВА И ПРАВА КОНЦА 1930-х -1980-х ГОДОВ
}

\begin{abstract}
Аннотация: В статье рассматривается теоретико-правовое осмысление проблем международного права в советском правоведении конца 1930-1980-х годов. Прошедшее в 1938 году под руководством А. Я. Вышинского совещание по вопросам науки советского государства и права открыло новый период развития советского правоведения. Наука права стала более практически ориентированной и отказалась от экономико-правовых кониепичй Е. Б. Пашуканиса и ряда других авторов, соединив марксизм с классическим правовым этатизмом. Общетеоретические нововведения затронули и проблемы теории международного права. Методологическую основу исследования составляют общенаучные и специальные методы познания, в частности, описательный и сравнительно-правовой методы, методы анализа и синтеза. Позитивистский подход советского правоведения проявился в критике проекта Декларации прав человека, значительное влияние на которую оказала естественно-правовая философия. Восприятие советским правоведением концепции государственного суверенитета, основанной на идеях Г. Еллинека, связано с международной политической обстановкой 1920-1930-х годов, в которой СССР был вынужден перейти от идеи мировой революичи к концепции мирного сосуществования. В более поздних теоретико-правовых исследованиях советских правоведов международное право не играло сущеественной роли. Исключение составляет конщепщия Л. С. Явича о сущности права, в которой автор стремится обосновать применимость к международному праву своей теории о трёх уровнях сущности права.

Ключевые слова: Международное право, общая теория права, советская теория права, юридический позитивизм, А. Я. Выиинский, Л. С. Явич, суверенитет, система права, С. С. Алексеев, права человека.

Abstract: The paper presents analysis of legal-theoretical reflection of the issues of international law in Soviet legal science of 1930-1980. The conference on the issues of the science of Soviet state and law of 1938 under the guidance of A.Y. Vyshinsky opened a new period of the development of Soviet jurisprudence. Legal science became more practically oriented, abandoned legal-economical conceptions of Y. B. Pashukanis and several more authors and combined Marxism with classical legal etatism. General theoretical innovations affected the problems of the theory of international law. Methodological basis of paper consists of general and special scientific methods, especially descriptional and comparative methods, methods of analysis and synthesis. Positivistic approach of Soviet jurisprudence appeared in the critic of the project of Declaration of Human Rights, influenced by the natural law philosophy. Soviet reception of the G. Jellinek's conception of state sovereignty was connected with international political situation of 1930's, when USSR had to shift from the idea of world revolution to the conception of peaceful coexistence. The role of international law in later Soviet legal-theoretical investigations was less important, except L. S. Yavich's conception of the essence of law. Keywords: Sovereignty, L. S. Yavich, A. Y. Vyshinsky, legal positivism, Soviet theory of law, general theory of law, international law, system of law, S. S. Alekseev, human rights.
\end{abstract}

Публикация подготовлена в рамках поддержанного РГНФ научного проекта №15-33-01372

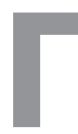
енезис общей теории государства и права исторически связан с развитием внутригосударственного права, в первую очередь гражданского и, уже позднее, государственного. Международное право по этой причине, а также ввиду наличия ряда существенных отличий от права внутригосударственного, зачастую выпадало из поля зрения теоретиков права, либо трактовалось как исключение из общей научной картины. В европейской юридической науке такое положение начало изменяться в первой половине $\mathrm{XX}$ века, во многом благодаря влиянию чистого учения о праве, неотделимого от Венской школы между- народного права (О Венской школе международного права см.: [3]). Теоретико-правовое осмысление международного права в отечественной юридической науке восходит к концу XIX и, в большей степени, к началу XX века, времени появления оригинальных теоретических концепций Н. М. Коркунова [21, с. 436-458], Г. Ф. Шершеневича [33], Л. И. Петражицкого [28], В. Д. Каткова [17] и других правоведов. Вместе с тем данные концепции не оказали значительного влияния на последующее развитие отечественного правоведения в силу исторически обусловленного двукратного разрыва академической преемственности 


\section{Право и политика $12(192) \cdot 2015$}

в 1917 и конце 1930-х годов. Настоящее исследование ставит своей целью прояснение вопроса об отражении международного права и проблем, связанных с ним в советской теории права и государства конца 1930x-1980-х годов.

\section{Развитие советской юриспруденции}

Послереволюционная советская юридическая наука носила ярко выраженный идеологический характер и была не столько развитием традиционной теорией права, сколько продолжением марксистского общественно-политического учения. По замечанию С. С. Алексеева, первоначально советская юриспруденция «выступала в виде леворадикальной революционной доктрины военно-коммунистического толка, объявлявшей право сугубо буржуазным явлением, обречённым на скорое «отмирание». Затем в конце 20-х - начале 30-х гг. она, сохраняя свою суть коммунистической доктрины, переросла в некий конгломерат подогнанных под «современность» марксистских догм, партийных директив и данных юридического позитивизма» [8, с. 37]. Наиболее значимыми и оригинальными концепциями этого периода были марксистская теория П. И. Стучки, меновая теория права Е. Б. Пашуканиса, классовопсихологическая теория права М. А. Рейснера [19, с. 838-851]; [27, с. 150-173]. Для данных концепций характерно следующее из марксизма рассмотрение права как элемента надстройки над общественным базисом - производственными отношениями и стремление редуцировать юридические понятия к тем или иным понятиям марксистской политической экономии (критический анализ марксистских правовых концепций, включая концепции указанных авторов, см. в [6]). Несмотря на высокую степень соответствия указанных концепций идеям К. Маркса и Ф. Энгельса [6, с. 122-123], ортодоксальное марксистское правоведение в весьма низкой степени коррелировало с традиционной юриспруденцией и не отвечало возникавшим перед советской юриспруденцией проблемам практического характера.

Новый период развития правоведения в СССР начался с «II совещания по вопросам науки советского государства и права», прошедшем 16-19 июля 1938 года под руководством Прокурора СССР А. Я. Вышинского. Несмотря на декларативное сохранение приверженности марксистской правовой доктрине, в качестве основы «генеральной линии» советской юридической науки была взята традиционная правовая догматика, основанная на правовом этатизме [8, с. 40-41]. Прежнее марксистское правоведение под- верглось критике, его представители были обвинены в «фальсификации марксизма-ленинизма» [12, с. 75], «вредителями, подвизавшимися на правовом теоретическом фронте» [12, с. 79] и даже «троцкистско-бухаринскими изменниками» $[12$, с. 65]. На совещании были определены основные теоретические принципы наук теории государства и права, международного права и всех отраслевых юридических наук - государственного права, уголовного права, гражданского права и т. д., которые продолжали оказывать прямое и существенное влияние на советскую правовую доктрину вплоть до конца 1970-х годов [25].

Особенное влияние совещания 1938 года на советскую доктрину международного права связано с тем, что его организатор и руководитель, А. Я. Вышинский, в 1940 году был назначен первым заместителем народного комиссара иностранных дел СССР, а в 1949-1953 годах возглавлял Министерство иностранных дел СССР.

\section{Понятие права. Правовой этатизм}

Одним из важных результатов унификации советской науки в 1938 году стала выработка общего понятия права. Под правом было решено понимать «совокупность правил поведения, выражающих волю господствующего класса, установленных в законодательном порядке, а также обычаев и правил общежития, санкционированных государственной властью, применение которых обеспечивается принудительной силой государства в целях охраны, закрепления и развития общественных отношений и порядков, выгодных и угодных господствующему классу» [12, с. 83]. Данное определение с незначительными корректировками воспроизводилось во всех последующих советских учебниках и монографиях по теории государства и права (см. напр.: [14, с. 156]; [16, с. 59]; [34, с. 110]; [9, с. 97]), а попытки его пересмотра (до конца 1980-х годов) носили форму введения параллельного «более широкого» определения, не исключающего «узконормативное» определение А. Я. Вышинского [25].

Данное определение выражает классическую доктрину правового этатизма (как исторической формы юридического позитивизма), дополненную элементами марксизма, главным из которых было указание на «волю господствующего класса», ссылка на которую содержится в Манифесте Коммунистической партии [26, с. 55]. Доктрина правового этатизма (то есть рассмотрения права и государства как двух различных явлений, первое из которых производно от второго) восходит к трудам английского правоведа Дж. Остина, 
определявшего право как команду суверена политически независимого общества [1, p. 116]; [2, p. 5-6]. Остин проводит чёткую границу между правом и моралью $[1$, p. 84-85]. Задачу юридической науки он видит в изучении позитивного права, независимо от того, хорошее оно или плохое. По аналогии с юриспруденцией он считает необходимым и построение этической науки - она должна заниматься изучением позитивной морали [1, р. 85]. Отличием права от морали является происхождение правовых норм - команда суверена, поэтому в частности международному праву Остин отказывает в праве именоваться правом: с его точки зрения, в силу отсутствия международного суверена, правильнее говорить о международной морали [1, p. 85]. Именно суверен становится центральным элементом теории Остина. Сувереном может быть как отдельное лицо, так и совокупность лиц, ключевой же характеристикой суверена является привычка повиновения ему со стороны политически независимого общества [1, p. 116] (о соотношении «независимого политического общества» с государством у Остина см. [18, с. 447-449]).

Правовой этатизм как и любая другая форма юридического позитивизма, характеризуется четырьмя отличительными признаками, он: 1) отрицает необходимую концептуальную связь между правом и моралью, а также целесообразность ее установления; 2) считает вопрос о том, что является правом и что им не является, вопросом социального факта; 3) исходит из того, что методология юридической науки не позволяет познать объективно правильное естественное право или мораль, поскольку 4) основывается на анализе фактов и не обращается к метафизическим вопросам [24].

В качестве примера позитивистского подхода советской доктрины международного права можно привести критику со стороны делегации СССР проекта Декларации прав человека, составленной под значительным влиянием естественно-правовой доктрины прав человека. Естественный характер прав человека, защищаемых Декларацией, советской делегацией решительно отвергается: «Иногда слышатся возражения такого рода, что вопросы государства не должны затрагиваться Декларацией прав человека потому, что эта Декларация посвящена правам человека. Но с такого рода позицией нельзя согласиться уже по одному тому, что права человека немыслимы вне государства. Самое понятие права есть понятие государственное. Больше того, права человека немыслимы без того, чтобы они не пользовались защитой и охраной со стороны государства. В противном случае права человека превращаются в пустую абстракцию, в ничего не значащую иллюзию, которые, как известно, легко создаются, но также легко и исчезают» [13, с. 380].

В числе крупных недостатков представленного для обсуждения проекта советская делегация отметила абстрактное построение ряда его статей, отсутствие указания на конкретные меры, которые должны быть приняты для обеспечения осуществления соответствующих прав:

«Большинство третьего комитета отклонило другую, как я сказал, более существенную часть этого предложения, которая указывала на обязанности государства и общества принять все необходимые меры, в том числе и законодательные, для того, чтобы обеспечить каждому человеку реальную возможность пользования всеми правами, указанными в Декларации. Это оказалось отклоненным, это оказалось отброшенным в сторону. Что же осталось? Осталось голое провозглашение, то-есть именно то, что составляет самую слабую сторону этой Декларации, - остались тенденция, пожелание, возглас, лозунг, но не статья, та статья, которая могла бы внушить уверенность в том, что действительно будут обеспечены те блага, которые провозглашаются в этой 23-й статье. Это все отброшено. Нет в этой статье главного - именно указания на то, что общества и государства обязаны принять меры, в том числе и законодательные, в целях обеспечения возможности свободного развития личности в экономической, социальной и культурной областях. Это все, я говорю, отброшено» [13, с. 369]. Характеризуя работу комитета, готовившего проект Декларации, Вышинский отмечает: «Оно [большинство комитета] предпочло тому пути, на который советская делегация все время пыталась толкать работу третьего комитета, - пути конкретного, положительного решения вопроса о тех рекомендациях, - хотя бы чисто морального порядка, - которые нужно дать другим государствам, чтобы они следовали этому пути, путь абстрактный, усеянный цветами пышной фразеологии, которая была более уместна полтораста лет тому назад, которая сейчас уже никого не может прельстить, ибо все эти фразы и формулы эпохи французской революции, эпохи американской революции и английской революции XVII века сейчас уже поблекли, потому что живая жизнь показала, что за этими звонкими формулами скрывается жестокая действительность, разрушающая фетиши и иллюзии» $[13$, с. 370].

Приведённые цитаты из выступлений А. Я. Вышинского основаны на восходящей к одному из основоположников юридического позитивизма, английскому философу и правоведу И. Бентаму, традиции критики законодательной практики, основанной на есте- 


\section{Право и политика $12(192) \cdot 2015$}

ственно-правовой теории. Проанализировав такие известные акты, как французская «Декларация прав и свобод человека и гражданина» 1789 г., «Декларация независимости» США 1776 г., «декларации прав» штатов Северная Каролина, Виргиния, Массачусетс и Пенсильвания, Бентам пришёл к выводу, что эти попытки оказались крайне неудачными. Причины неудачи состоят в том, что вместо определённости конкретных законов здесь предлагаются тёмные и неясные положения, которые могут пониматься людьми очень по-разному, иными словами: «оставьте букву, и они [законы] выразили бы не что иное, как если бы каждый человек сказал: «Ваши законы сделаются пустыми ipso facto, как скоро они заключает в себе что-нибудь не по моему вкусу»» [11, с. 404-407]; [4, p. 306-309]. Отдельное исследование Бентам посвятил «Декларации прав и свобод человека и гражданина» [3]; [32, с. 340-343]. Последовательно разбирая каждый её пункт, Бентам указывает на то, каким образом данное положение может привести к абсурдным анархическим последствиям при его буквальном понимании. В качестве примера можно привести анализ первой статьи «Декларации»: «Люди рождаются и остаются свободными и равными в правах. Общественные различия могут основываться только на соображениях общей пользы» [31, с. 86]. Ни один человек, возражает Бентам, никогда не был рождён свободным и свободным не оставался на протяжении жизни: ни ребёнок, полностью зависящий от своих родителей, ни взрослый, живущий под властью правительства своей страны. Не рождаются люди и равными в правах: можно ли говорить о равенстве в правах наследника богатой и бедной семьи? Не существует равенства в правах и среди взрослых: нет равенства между опекуном и подопечным, между офицером и солдатом, между мужем и женой. Оговорка же о том, что различия могут быть основаны на общей пользе, означает то, что первая часть статьи не имеет вообе никакого значения: равенства в правах не существует [3, p. 53-55].

\section{Концепция государственного суверенитета}

Международно-правовая проблематика совещания 1938 года, а также совещания 1948 года, посвящённого обсуждению макета учебников по теории государства и права [12, с. 396-418] связана в первую очередь с понятием государственного суверенитета, играющего важную роль в науке теории государства и права, науке международного права и государствоведении.

А. Я. Вышинский критикует концепцию государственного суверенитета как фактической и юридической способности государства сделать свою волю обязательной для всех, на кого его власть простирается, предложенной рядом авторов [12, с. 404]. Данная позиция отождествляется им с русской школой государствоведения Градовского, Коркунова, Кокошкина и др. [12, с. 404-405], хотя в действительности определения суверенитета названных им дореволюционных правоведов весьма близки к концепции Еллинека и собственному определению Вышинского (так, например, Ф. Ф. Кокошкин отмечал, что «понятие суверенитета... чисто отрицательное, - суверенная власть есть независимая власть; над ней не стоит никакой другой власти») [20, c. 242]; [22, с. 26]. В противоположность указанной теории Вышинский обращается к теории немецкого правоведа Г. Еллинека [15, с. 457] (не называя его), в соответствии с которой суверенитет представляет собой скорее негативное понятие, указывающее на состояние независимости данной государственной власти от всякой другой власти как внутри, так и вне границ этого государства [12, с. 405]. Критика Вышинского основана на предположении о том, что из определения суверенитета как «способности государства» следует, что отсутствие фактической способности государства своими силами защитить осуществление своей власти означает отсутствие у него суверенитета, что, в свою очередь, ставит под сомнение наличие суверенитета у слабых государств и даёт повод для агрессивных притязаний государств сильных [12, с. 405].

Критикуя в 1938 году учебник международного права Е. А. Коровина [23], Вышинский считает неприемлемыми утверждения автора о том, что из понятия суверенитета не следует делать незыблемой догмы, а к интервенции подходить чисто исторически, оценивая её исходя из опыта советской республики [12, с. 96]. По мнению Вышинского интервенция неприемлема ни при каких обстоятельствах и является грубым нарушением международного права и суверенитета соответствующего государства [12, с. 95-98]. Необходимо отметить, что обоснование данного положения носит у Вышинского не теоретический (юридический), а практический (политический) характер, что проливает свет на тот акцент, который в целом делался данным правоведом на незыблемости государственного суверенитета. Учебник Е. А. Коровина был издан в 1924 году, на его написание повлияла ранняя большевистская внешнеполитическая доктрина, часто ассоциируемая с Л. Д. Троцким, исходившая из непримиримого антагонизма между советским государством и капиталистическим государствами, рассчитанная на скорое осуществление мировой социалистической 
DOI: 10.7256/1811-9018.2015.12.17317

При цитировании этой статьи сноска на doi обязательна

Правовая и политическая мысль

революции, поддерживать которую (естественно, в форме интервенций) должно было советское государство [29, с. 83-88]. Вместе с тем, после того, как стало ясно, что всемирная революция не осуществится в краткосрочной перспективе, советская внешняя политика осуществила разворот в сторону концепции мирного сосуществования и установления двусторонних отношений с капиталистическими странами [29, с. 105-109]. Как отмечал Вышинский, «при разработке советской науки международного права необходимо исходить из факта капиталистического окружения, в котором находится СССР и которое определяет международное положение Советского Союза, надо исходить из борьбы или соревнования между двумя системами - социалистической и капиталистической, как и из факта всё большего разворота сотрудничества СССР с теми или иными капиталистическими странами как в области экономических отношений, так и в деле сохранения мира... В «Международном праве переходного времени» проф. Коровин... исходил из принципов игнорирования реальной, исторически сложившейся международной обстановки... Проф. Коровин выдвигает концепцию международного социалистического права, которое, как это само собой понятно, должно исходить не из сотрудничества СССР с теми ли иными капиталистическими странами, а из полного игнорирования этого сотрудничества, из противопоставления себя остальному миру... Это рецидив «левацких» заскоков автора, довольно невинного по части основных принципов ленинскосталинской международной политики» [12, с. 97-98]. Таким образом, можно сделать вывод, что теоретический акцент на незыблемости государственного суверенитета, вызван прагматическими соображениями, а именно - опасениями интервенции в СССР со стороны капиталистических стран.

Повышенное внимание к понятию государственного суверенитета (и акцент на недопустимости его нарушения) в советской правовой науке, будучи производным от внешней политики СССР, в свою очередь, стал важной частью советской международно-правовой доктрины. Критикуя проект Декларации прав человека Вышинский от имени делегации СССР отмечал, что серьёзным недостатком проекта является «отсутствие каких-либо указаний на связь прав человека с проблемой государственного суверенитета» [13, с. 379-380]. Причину отсутствия такого указания Вышинский усматривал в возрождении теории отрицания государственного суверенитета, служащую, по его мнению, целям мирового господства, политического и экономического подчинения более слабых государств [13, с. 380-382].

\section{Природа международного права, его место в системе права}

Установление на совещании 1938 года основных принципов научной работы в области правоведения не могло, конечно, исчерпать круг проблем науки теории государства и права. Одной из таких проблем оставалась относительная отвлечённость советских теоретико-правовых исследований от вопросов специфики международного права и его роли в построении единой теоретико-правовой научной картины. К сожалению, попытки теоретикоправового осмысления феномена международного права носили единичный характер, ограничиваясь, как правило, указанием на возможность применения общетеоретических методов к анализу международного права (см. напр.: [30, с. 177-190]), либо составлением того или иного варианта системы права, включающего в себя международное право (см. напр.: [14, с. 301-302]). С. С. Алексеев, в работах которого советские теоретико-правовые исследования системы права нашли наиболее полное и законченное выражение, в монографии 1975 года «Структура советского права» резюмировал положение международного права следующим образом: «Международное публичное право - это вообще не отрасль права. Как правильно отмечено в литературе, международное право есть особая правовая система, особая область права, автономная по отношению к праву внутригосударственному (национальному)... Под углом зрения своих системно-структурных характеристик международное публичное право - такое социальное образование, которое занимает равное положение с любой национальной правовой системой. Поэтому в принципе к определению структуры международного публичного права следует подходить с тех же позиций, с каких освещается структура национальных правовых систем» [10, с. 179]. Из данного положения правовед делал вывод о том, что международное право (межгосударственная правовая система) подразделяется на отрасли, подотрасли и институты, которым должны соответствовать специальные научные дисциплины [10, с. 179].

В качестве исключения необходимо отметить концепцию ленинградского правоведа Л. С. Явича, который, в определённой мере развивая марксистскую экономико-правовую традицию в теории права, обосновывал сущность права как единство объективного и субъективного права, которая выражается на трёх уровнях - политических, социальных и экономических отношений [35, с. 80-98]. 


\section{Право и политика $12(192) \cdot 2015$}

Генезис международного права связывается Л. С. Явичем с международными экономическими отношениями, прообразом которых является межплеменной обмен, возникший одновременно с разделением труда [35, с. 171-178]. Неразвитость межгосударственных материальных отношений древнего мира и средневековья предопределяла недостаточную устойчивость политических отношений и слабость международного правопорядка, вплоть до возникновения капитализма, который, по крайней мере на раннем этапе своего развития, вёл к укреплению суверенитета государств и равноправию субъектов международных отношений, а также к стремлению к стабильным и мирным отношениям [35, с. 178]. Собственно к возникновению международного правопорядка привело «развитие производственных отношений глобального свойства, выходящих за государственные границы» [35, с. 179].

В сущности международного права, по мнению правоведа, следует различать, как и применительно к внутригосударственному праву, три порядка. Его сущность первого порядка носит классово-волевой характер, представляя результат согласования волеизъявлений суверенных государств (их господствующих классов). Международное право охраняется силой государств, образующих международное сообщество и непосредственно заключивших двухсторонние или многосторонние соглашения [35, с. 179]. Сущность международного права второго порядка связана с «общесоциальным правом», лежащими в основе международного права правах народов, наций, человека, которые сами по себе не носят юридического характера: право народов на самостоятельность и безопасность, право наций на самоопределение и образование суверенной государственности, комплекс прав и свобод человека. Общесоциальное право находит своё выражение как в юридически обязательных международных договорах, так и «в документах (в декларациях), которые, сами по себе не придают им юридического, общеобязательного для государств значения, но обладают большой силой морально-политического, идейного влияния не только на отношения между государствами, но также на внутригосударственные отношения» $[35$, c. 180]. Сущностью международного права третьего и самого глубинного порядка (экономического), в соответствии с концепцией Л. С. Явича, являются «имеющие правовую природу отношения собственности, складывающиеся в между- народном общении и являющиеся юридическим выражением специфических производственных отношений, обусловленных международным разделением труда и обменом» [35, с. 180]. При этом так же как и внутригосударственное право, международное право имеет две стороны проявления своей сущности - объективное и субъективное право [35, с. 180].

\section{Концепция общих дозволений и запретов}

Частные достижения советской теории права, к сожалению, так же как и её общие концепции, не нашли своего прямого приложения к проблемам теории международного права. Исключением здесь является концепция общих дозволений и общих запретов С. С. Алексеева.

Дозволения и запреты рассматриваются С. С. Алексеевым (наряду с позитивным обязыванием) как элементы системы правового регулирования, к которым оно может быть сведено [10, с. 264-265]. В соответствии с концепцией автора, не существует дуализма запрета и дозволения, то есть из отсутствия запрета само по себе не следует, что то или иное поведение является дозволенным. Данная теория резко контрастирует с концепцией негативного правового регулирования Г. Кельзена, в соответствии с которой на лицо не может быть возложена правовая обязанность, не предусмотренная правопорядком, а значит, при отсутствии запрета поведение является (негативно) разрешённым [7, p. 147-148]. С. С. Алексеев проводит различие между состояниями, когда данное поведение охватывается правовым регулированием и не охватывается, а в случае, если охватывается - между зонами интенсивного и неинтенсивного правового регулирования [10, с. 281-286]. Общие дозволения и общие запреты, в свою очередь, являются «исходным и направляющим правовым началом на данном участке общественных отношений» [10, с. 295]. Принципиально важным положением данной концепции является то, что общие дозволения и запреты существуют не всегда и об их существовании нельзя сделать вывод просто на основании наличия соответствующей частной противоположности - частные запреты и дозволения сами по себе не должны рассматриваться как исключения, свидетельствующие о существовании общего правила [10, с. 303-307]. В качестве одного из примеров применения данной теоретической концепции С. С. Алексеев приводит вопрос о международноправовом регулировании использования космического пространства в военных целях. Из того факта, что в данной области установлены только частичные 
запреты (например, запрет военной деятельности на Луне) рядом авторов делались выводы о возможности размещения в космосе военных объектов. Возражая против них, С. С. Алексеев указывает, что «область космического пространства еще не является зоной активного регулирования, которое здесь пока лишь складывается, формируется». При этом, по мнению правоведа, «в условиях, когда юридическое регулирование только складывается, частичные запреты могут быть свидетельством не противостоящего им ОбД [общего дозволения], а, напротив, началом, первыми кирпичиками формирующегося ОбЗ [общего запрета]» $[10$, с. 307]. В качестве возможного критерия для выявления будущего направления правового развития С. С. Алексеев называет «социальное регулирование данной области в целом, его качественные особенности и инфраструктура, и прежде всего сложившиеся нравственные принципы», при этом, по мнению автора, в данном случае очевидным является то, что в современную эпоху одним из ведущих международно-моральных принципов является стремление к миру, противодействие войне и военным приготовлениям [10, с. 308].

\section{Заключение}

Проведённое нами исследование позволяет сделать следующие выводы

Советская теория права, в том числе, в части теоретического осмысления международного права, после конца 1930-х годов развивалась под определяющим влиянием «II совещания по вопросам науки советского государства и права», прошедшем в 1938 году под руководством А. Я. Вышинского. Существенное влияние на теорию права и на доктрину международного права оказали выработанное на данном совещании определение права (предполагающее правовой этатизм) и сделанный на нём акцент на понятии государственного суверенитета и недопустимости интервенции. Последующее развитие теории права в СССР дополнило теоретико-правовую рефлексию относительно международного права выяснением места международного права с точки зрения советских концепций системы права, концепцией сущности международного права Л. С. Явича и применением к международному праву концепции общих дозволений и запретов С. С. Алексеева.

\section{Библиография:}

1. Austin J. Lectures on Jurisprudence and Philosophy of Positive Law. Jersey City: Frederic D. Linn \& Company, 1875. 364 p.+lvi.

2. Austin J. The Province of Jurisprudence Determined. London, 1832. 391 p.

3. Bentham J. Anarchical Fallacies // 'Nonsense upon Stilts': Bentham, Burke and Marx on the Rights of Men / Ed. by J. Waldron. London, 1987. P. 46-76

4. Bentham J. Principles of Legislation. Boston, 1830. 310 p.

5. Bernstorff J., von. The Public international Law Theory of Hans Kelsen: Believing in Universal Law. Cambridge, 2010. 324 p.

6. Kelsen H. The Communist Theory of Law. New York, 1955. 203 p.

7. Kelsen H. General Theory of Law and State. New Brunswick: Transaction Publishers, 2005. 516 p.

8. Алексеев С. С. Восхождение к праву. Поиски и решения. М.: 2001. 752 с.

9. Алексеев С. С. Общая теория права. В 2-х т. Т. 1. М., 1981. 360 с.

10. Алексеев С. С. Собр. соч. В 10 т. Т. 2. М., 2010. 470 с.

11. Бентам И. Введение в основания нравственности и законодательства. М., 1998. 415 с.

12. Вышинский А. Я. Вопросы теории государства и права. М., 1949. 418 с.

13. Вышинский А. Я. Вопросы международного права и международной политики. М., 1951. 799 с.

14. Голунский С. А., Строгович М. С. Теория государства и права. М., 1940. 304 с.

15. Еллинек Г. Общее учение государстве. СПб.: Издательство «Юридический центр Пресс», 2004. 752 с.

16. Иоффе О. С., Шаргородский М. Д. Вопросы теории права. М., 1961. 381 с.

17. Катков В. Д. К анализу основных понятий юриспруденции. Харьков, 1903. 462 с.

18. Кельзен Г. Чистое учение о праве и аналитическая юриспруденция // Российский ежегодник теории права. № 2. 2009. С. $432-453$.

19. Козлихин И.Ю., Поляков А.В., Тимошина Е.В. История политических и правовых учений. Учебник. СПб.: Издательский дом Санкт-Петербургского государственного университета, 2007. 854 с.

20. Кокошкин Ф. Ф. Избранное /сост. А. Н. Медушевский. М., 2010. 592 м.

21. Коркунов Н. М. Сборник статей Н. М. Коркунова. СПб., 1898. 568 с.

22. Коркунов Н. М. Русское государственное право. Т. 1. Введение и общая часть. Изд. 6-е. / под ред. и с доп. М. Б. Горенберга. СПб.: Типография М. М. Стасюлевича, 1909. 623 с.

23. Коровин Е. А. Международное право переходного времени. М., 1924. 139 с.

24. Краевский А. А. Чистое учение о праве Ганса Кельзена и современный юридический позитивизм. Диссертация на соискание учёной степени кандидата юридических наук. СПб., 2014. 231 с.

25. Круглый стол «Советского государства и права» «О понимании советского права» // Советское государство и право. 1979. № 7. С. 56-74; № 8. С. 48-77.

26. Маркс К., Энгельс Ф. Манифест Коммунистической партии. М., 1958. 72 с. 
DOI: $10.7256 / 1811-9018.2015 .12 .17317$

При цитировании этой статьи сноска на dоі обязательна

27. Нерсесянц В. С. Общая теория права и государства. М, 2002. 552 с.

28. Петражицкий Л. И. Теория права и государства в связи с теорией нравственности. СПб.: Издательство «Лань», 2000. $608 \mathrm{c.}$

29. Сидоров А. Ю., Клеймёнова Н. Е. История международных отношений 1918-1939 гг. М., 2008. 640 с.

30. Тилле А. А., Швеков Г. В. Сравнительный метод в юридических дисциплинах. М., 1973. 192 с.

31. Хрестоматия по истории государства и права зарубежных стран: в 2 т. / Отв. ред. д.ю.н., проф. Н. А. Крашенинникова. T. 2: Современное государство и право / Сост. Н. А. Крашенинникова. М., 2004. 672 с.

32. Чичерин Б. Н. История политических учений. Т. 2. СПб., 2008. 752 с.

33. Шершеневич Г. Ф. Общая теория права. Т. 1. М., 1910. 512 с.

34. Явич Л. С. Общая теория права. Л., 1976. 286 с.

35. Явич Л. С. Сущность права. Социально-философское понимание генезиса, развития и функционирования юридической формы общественных отношений. Л., 1985. 207 с.

\section{References (transliterated):}

1. Austin J. Lectures on Jurisprudence and Philosophy of Positive Law. Jersey City: Frederic D. Linn \& Company, 1875.364 p.+lvi.

2. Austin J. The Province of Jurisprudence Determined. London, 1832. 391 p.

3. Bentham J. Anarchical Fallacies // 'Nonsense upon Stilts': Bentham, Burke and Marx on the Rights of Men / Ed. by J. Waldron. London, 1987. P. 46-76

4. Bentham J. Principles of Legislation. Boston, 1830. 310 p.

5. Bernstorff J., von. The Public international Law Theory of Hans Kelsen: Believing in Universal Law. Cambridge, 2010. 324 p.

6. Kelsen H. The Communist Theory of Law. New York, 1955. 203 p.

7. Kelsen H. General Theory of Law and State. New Brunswick: Transaction Publishers, 2005. 516 p.

8. Alekseev S. S. Voskhozhdenie k pravu. Poiski i resheniya. M.: 2001. 752 s.

9. Alekseev S. S. Obshchaya teoriya prava. V 2-kh t. T. 1. M., 1981. 360 c.

10. Alekseev S. S. Sobr. soch. V 10 t. T. 2. M., 2010. 470 s.

11. Bentam I. Vvedenie v osnovaniya nravstvennosti i zakonodatel'stva. M., 1998. $415 \mathrm{~s}$.

12. Vyshinskii A. Ya. Voprosy teorii gosudarstva i prava. M., 1949. $418 \mathrm{~s}$.

13. Vyshinskii A. Ya. Voprosy mezhdunarodnogo prava i mezhdunarodnoi politiki. M., 1951. 799 s.

14. Golunskii S. A., Strogovich M. S. Teoriya gosudarstva i prava. M., 1940. 304 s.

15. Ellinek G. Obshchee uchenie gosudarstve. SPb.: Izdatel'stvo «Yuridicheskii tsentr Press», 2004. $752 \mathrm{~s}$.

16. Ioffe O. S., Shargorodskii M. D. Voprosy teorii prava. M., 1961. 381 s.

17. Katkov V. D. K analizu osnovnykh ponyatii yurisprudentsii. Khar'kov, 1903. $462 \mathrm{s.}$

18. Kel'zen G. Chistoe uchenie o prave i analiticheskaya yurisprudentsiya // Rossiiskii ezhegodnik teorii prava. № 2. 2009. S. 432-453.

19. Kozlikhin I.Yu., Polyakov A.V., Timoshina E.V. Istoriya politicheskikh i pravovykh uchenii. Uchebnik. SPb.: Izdatel'skii dom Sankt-Peterburgskogo gosudarstvennogo universiteta, 2007. $854 \mathrm{~s}$.

20. Kokoshkin F. F. Izbrannoe /sost. A. N. Medushevskii. M., 2010. $592 \mathrm{~m}$.

21. Korkunov N. M. Sbornik statei N. M. Korkunova. SPb., 1898. 568 s.

22. Korkunov N. M. Russkoe gosudarstvennoe pravo. T. 1. Vvedenie i obshchaya chast'. Izd. 6-e. / pod red. i s dop. M. B. Gorenberga. SPb.: Tipografiya M. M. Stasyulevicha, 1909. 623 s.

23. Korovin E. A. Mezhdunarodnoe pravo perekhodnogo vremeni. M., 1924. 139 s.

24. Kraevskii A. A. Chistoe uchenie o prave Gansa Kel'zena i sovremennyi yuridicheskii pozitivizm. Dissertatsiya na soiskanie uchenoi stepeni kandidata yuridicheskikh nauk. SPb., 2014. $231 \mathrm{~s}$.

25. Marks K., Engel's F. Manifest Kommunisticheskoi partii. M., 1958. 72 s.

26. Nersesyants V. S. Obshchaya teoriya prava i gosudarstva. M, 2002. 552 s.

27. Petrazhitskii L. I. Teoriya prava i gosudarstva v svyazi s teoriei nravstvennosti. SPb.: Izdatel'stvo «Lan'», $2000.608 \mathrm{s.}$

28. Sidorov A. Yu., Kleimenova N. E. Istoriya mezhdunarodnykh otnoshenii 1918-1939 gg. M., 2008. 640 s.

29. Tille A. A., Shvekov G. V. Sravnitel'nyi metod v yuridicheskikh distsiplinakh. M., 1973. $192 \mathrm{~s}$.

30. Chicherin B. N. Istoriya politicheskikh uchenii. T. 2. SPb., 2008. $752 \mathrm{s.}$

31. Shershenevich G. F. Obshchaya teoriya prava. T. 1. M., 1910. $512 \mathrm{s.}$

32. Yavich L. S. Obshchaya teoriya prava. L., 1976. $286 \mathrm{s.}$

33. Yavich L. S. Sushchnost' prava. Sotsial'no-filosofskoe ponimanie genezisa, razvitiya i funktsionirovaniya yuridicheskoi formy obshchestvennykh otnoshenii. L., 1985. 207 s. 